Journal of Indonesian Tourism and Development Studies doi: 10.21776/ub.jitode.2017.005.01.02

E-ISSN : 2338-1647

http://jitode.ub.ac.id

\title{
Questioning the Readiness of Manado as a Tourism Destination: Poor Service of Waitresses in the Local Restaurants
}

\author{
Benny Irwan Towoliu ${ }^{1 *}$, Fonny Sangari ${ }^{2}$, Dimas Ero Permana ${ }^{3}$ \\ Department of Tourism, State Polytechnic of Manado, Manado, Indonesia
}

\begin{abstract}
In the last two decades, Manado local government has forwarded a Manado vision as a tourism destination. Due to this policy, many accommodations and restaurants are built here. Certainly, this is an opportunity for local people to work in the hospitality industry. Meanwhile, so far the tourism development industry is only physical, it was not supported by the human resource local tourism development, in this case, the waitresses who work in local restaurants. The research aims to examine the quality of service of waitresses who work in local restaurants. The research was conducted from October to December 2015, and locations of the area where data were taken are Mega Mas and Sabua Bulu Malalayang. These areas are the centers of local culinary industry. The research method used is descriptive qualitative supported by quantitative data. Field research includes a survey involving 116 respondents, observation and documentation, and the analysis by servqual method. Service quality measured based on visitors' perceptions of the five dimensional aspects. They are the tangible aspect, responsiveness aspect, assurance aspect and empathy aspect. Result of this research shows that service quality of local waitresses are still low, where service performance appraisal is 3.11 while the guest expectations of service quality were 4.47. Guest rating on the performance expectations of service and quality of service shows a minus value. This indicates that the guest is not satisfactory with the performance of services provided by a waitress with an average value of 1.35 satisfactions which means that the value of service of local waitress is $\leq 0$. Recommendation is that the local governments should encourage business manager of local restaurants training to improve service quality of waitress. The methods of training suggested are video presentation, vestibule, role plays and case studies.
\end{abstract}

Keywords: local restaurants, poor service, readiness of Manado, tourism destination, waitresses.

\section{INTRODUCTION}

Manado is the capital of North Sulawesi province in the last two decades has forwarded a vision Manado as a tourism destination and also at the end of 2014 set as one of the organizers of MICE events in Indonesia. The city is famous with Bunaken as a marine national park, continuing to improve tourism industry sector. Specifically the hospitality industry and restaurants, until early 2015 there were 86 hotels and inns as well as 323 restaurants [1,2]. The culinary activities of local communities are very close to the culture of eating, so it has been made a culinary festival in this city, which in turn supports tourism in the city.

This is the basis for the government of Manado to establish tourism as a sector featured over the past 10 years. Currently, Manado government is too intense speeding up the construction. However, the development of tourism cannot only

\footnotetext{
* Correspondence address:

Benny Irwan Towoliu

Email: benny.tourism@gmail.com

Address: Campus of State Polytechnic of Manado, Buha Manado PO BOX 1256
}

be approached by the development of unique and beautiful location, but also by human activity involved in the tourism. During this time, the understanding of tourism is only in how to sell a unique and beautiful location with a variety of infrastructure facilities and infrastructure in that location, and forget the readiness of human as a operation engine to drive the tourism.

Tourism industry is also known as laborintensive industries that involve a lot of human resources in them that will interact with each other; including with tourists as a consumer. In addition, tourism is an industry in which the art of man who plays it. It must show an element of his art to play tourist's (guest's) emotions to always be loyal and travel to a destination [3].

Accommodation and catering (restaurant) are the two elements that play the key role of human resources involved to attract tourists (guests) to visit. Inherent factor for human resources is the attitude of hospitality. This attitude is very enforced standards in hotel or restaurant business. A worker in a hotel or restaurant should always apply the standard in interacting with tourists. It 
means is how it shows that workers are friendly, polite and emphatic in serving tourists (guests).

So far quality service standards apply only to the order of the hotel industry. While in the food service industry (culinary) did not seem so considered. This trend occurred at various local restaurants in Manado city. The stake holders in the local culinary businesses hire employees noticed that the service quality does not good, actually the service will also affect the business carried on.

Several cases that occur at this time, so many workers from outside the city of Manado dominated jobs in the restaurant industry. Especially in well known restaurants and shaped the franchise, it is very rare for the original local employees. It is common knowledge that the information obtained by human resources (workers) are not ready to work in the local culinary industry. The low quality of service is extremely felt by guests who enjoy the culinary of Manado. It is not only felt by new visitors, but also local people who enjoy the local culinary prove that the quality of services delivered by local workers is far below the standard of a culinary industry. Moreover the city government strongly supports the development of original culinary of Manado as a tourist attraction besides marine attraction. Given the local restaurants offer very competitive products with the franchise from outside the area, in terms of visitors who come to enjoy a menu that is offered, then the local workers also need to be considered, so that a single package of quality services.

Ten major factors which determine the quality of services are: (1) reliability, includes two main things, namely consistency of work and the ability to be trusted. This means the company provides its services right since the first moment. Furthermore the company fulfills its promise, for example, deliver the service in accordance with the agreed schedule, (2) responsiveness, namely the willingness or readiness of employees to provide the services required by customers, (3) competence, means that everyone in a company has the skills and knowledge needed in order to provide certain services, (4) access, including ease of contact and encounter. This relates to the location of service facilities within easy reach, the waiting time is not too long, the communication channels of the company can easily be reached, and others, (5) courtesy, including politeness and courtesy, respect, attention and hospitality owned by the contact personnel (such as receptionist and telephone operators), (6) communication, it means that company provides information to customers in a language that can be understood. In addition, always listen to suggestions and complaints of customers, (7) credibility, namely the nature of honest and trustworthiness. Credibility includes the company name, company reputation, personal characteristics personal contact and interaction with customers, (8) security, which is safe from danger, risk, or hesitancy. These aspects include physical security, financial security, and confidentiality, (9) understanding, the customer is the effort to understand customer needs and (10) tangibles, the physical evidence of the service, could in the form of physical facilities, equipment used, and the physical representation services [4].

Furthermore, in its development, the overall factor is summarized in five dimensions. These five key dimensions of service quality are: (1) tangible (direct evidence), formed the appearance and capabilities of facilities, equipment, tools and facilities and physical infrastructure that is reliable, (2) reliability, the ability to provide promised service with immediate, accurate and reliable including timeliness, the same service to all customers, the level of error skimpy and other things, (3) responsiveness, namely providing fast service to customers and understand what necessary, could include responsiveness, awareness serve and other matters, (4) assurance (collateral) is the guarantee will get the service properly and appropriately so as to develop a sense of trust and comfort for the customers, could include knowledge, skills, politeness, and nature trustworthy owned by the staff, free from danger, risk or doubt and (5) empathy, is giving special or personal attention to its customers in terms of satisfying consumer needs. Empathy also includes the communication, contacts and presence and understand what they need [5].

The relationship between the product with the service that the service company in providing products divided into two parts, namely the construction of service and service delivery, in other words the total quality of service is determined by a relatively construction service 
(service design) and service delivery. Construction services consist of construction products, construction of facilities, construction process and construction process operations services to customers. Construction services and delivery services is related to the other in shaping the service quality [6].

Culinary is part of the attraction of a destination, which is in development is strongly influenced by the service provided is good from food products offered as well as human resource airport (delivery). The customer satisfaction also affects the development of a tourist destination, in a comprehensive manner in future.

Previous study highlighting the lack of assurance and empathy on Chinese fast food, so they suggest the need for spending on training both for the quality of food and food supervisors to be trained [7]. Markovic, Raspor and Segaric highlights the quality of service in Croatia with the advanced measurement Restaurants Serqual and Dine-Serv modified [8]. They find that there is a gap between the expectations and the reality of the respondents, which the service expectation too high, while in fact the result of the service is low. This research despite the small sample with limited geography they also provide recommendations for improvement against the food industry in Croatia.

Service products have different characteristics from other tangible products. The characters are: (a) intangible, in a sense that services are intangible and cannot be touched, but can only be felt through the process provided by the service provider, (b) heterogeneous, because the service is generated by humans, the results from a ministry that is done will be different results depending on the perception to receive it, where these perceptions will be affected by the experience and knowledge of each recipient of the service, (c) Produced as consumed or integral (simultaneous production and consumption), product service is a service process itself in terms of when the provider of manufacturing services, at the same time service products sold and (d) vulnerable (perish ability), a service cannot be stored, sold, or returned, because it is not able to separate between production and consumption [9].

Related to the them the product is a collection of goods and services consisting of several formations, namely: (a) supporting Facility, a support facility that can be consumed or used by consumers is often called means of support, (b) facilitating Goods, a suggestion physical must be provided for the benefit of service delivery or what is often called the infrastructure, (c) explicit service, a service provided by a real (product key services) and can be felt perpetually directly by consumers, and (d) implicit service, a form of indirect services whose shape is more unreal but can be perceived by the consumer and explicit support service [10].

The quality of service is the use of the product suitability to meet customer needs and satisfaction. Matches are based on the use of five main characteristics, namely; (1) technology, which is the strength or endurance, (2) psychological, namely the image of race or status, (3) time, namely reliability, (4) contractual, namely the guarantee, and (5) ethics, the manners, friendly and honest [5].

Suitability of use of a product is when the product used has a long durability, the products used will enhance the image or status of consumers who wear them, the product is not easily broken, having quality assurance and in accordance with ethical when used. Especially for services, needed services to customers are welcome, polite and responsive to customer complaints, which may be pleasant or satisfying the customer. Referring to the service, the level of good service quality will always be seen and measured from the consumer side as well as the fulfillment of satisfaction with the service received.

The meaning of feeling happy or disappointed is a result of someone's comparison between the achievements or products felt and is expected [5]. Quality is fully customer satisfaction. A quality product is a product that can provide utmost satisfaction to the consumer, which is in accordance with what consumers expect of a product [5]. Quality is something that must be done properly by the service provider. Application quality as the nature and appearance of the product or the performance of a key part of the company's strategy is to achieve sustainable excellence, both as a market leader as well as a strategy for growth. The advantages of a product depend on the uniqueness of the quality services that are shown, namely the suitability of the premises expectations or desires of consumers. 
One way of selling the services of a company superior to its competitors is by providing quality service and quality, which meet the level of consumer interest. The level of consumer interest towards the services they receive can be formed based on the experience and advice they receive. Consumers choose a service provider based on the ranking of interest. And after enjoying the services they tend to compare it with what they expect.

The level of service quality cannot be judged based on the viewpoint of the company but should be viewed from the perspective of the customer ratings. Therefore, in formulating a strategy and program service, the company must be oriented to the interests of customers by paying attention to service quality components.

In the service concept, the role of the perpetrators service is of no less importance, as players will directly deliver services products to consumers. In a series of service are important aspects, namely the perpetrators of service or human resources itself [11].

One aspect to note is the problem of training of human resources in order to increase the performance of the service process. The important thing to note is the knowledge and skills of human resources. Referring to of the approach, it can be said that the formation of the delivery of services performed by the actors and the affected service will be based on the ability or competence of human resources which can be formed from educational background. While the service process itself also influences the formation of the functional aspects of service quality, such as consumer contact, attitudes, internal relations, behavior, service mindedness, appearance, accessibility [12]. There are four strategies for improving human resources to create customer satisfaction. The fourth strategy is to hire the right employees, building workers to deliver services properly, providing system services that support and retain workers who have the capability [13]. The purpose of this study examines service quality of waitresses at local restaurants to support the development of tourism destination in Manado.

\section{MATERIAL AND METHODS}

The research location was in the city of Manado where besides Bunaken National Park as a leading tourist destination, Manado also relies culinary as an alternative tourism to be enjoyed by the tourists. This research took the two places at the culinary center's namely Mega Mas and Sabua Malalayang area. The choice of location is deliberately based on several considerations, namely (1) it is a locally-based culinary location, and (2) the location of the area is used as a culinary tourism in the city of Manado.

The approach used in this study is a qualitative and quantitative because in determining the value of perception, the perception of the size of the respondents used the Likert scale [14]. Sampling technique accidental a sampling is sampling which done deliberately to the population encountered/ related to the research objectives. The concept of five dimensions of service will be used to assess aspects of the service provided a waitress in a series of service activities in the restaurant area at Sabua Malalayang and Mega Mas Manado. The data collection method was done by: observation, open interviews, and questionnaires. Sample sizes (respondents) taken amounted to 116 diners at two specified locations mentioned in Culinary Region Sabua Bulu and Mega Mas Manado. Research tools used are interview guides and questionnaires. The analytical method used is Likert scale and servqual methods. The questioner was tested by validity and reliability test.

\section{RESULTS AND DISCUSSION Respondents Character}

The characteristics of respondents in this study can be grouped into several groups: gender, age, education level, occupation and region of origin. Thus, based on the problems and the expected goals then the following is illustrated profile of the 116 respondents including: gender, the majority of respondents felt that the waitresses of culinary are dominated by women, $51.72 \%$ and men $48.28 \%$, it indicates that women prefer the street activity; hanging out at the same time sitting and eating in the city of Manado.

Then age affect people's motives also assess the waitresses, who work, as well as maturity in judgment objectively based on the experience of working, interacting with other cultures. Respondents aged $41-50$ years was $37.93 \%$, age $31-40$ years is $34.48 \%,>51$ years of age are $15: 52 \%$ and up to 20 years $1.72 \%$.

From the level of $43.10 \%$ of undergraduate education, postgraduate diploma $24.14 \% 19.83 \%$, 
while the senior high school only $12.93 \%$. At work, professions influence people to spend time after routine work that takes a lot of time. Profession as the private sector has contributed $28.45 \%$. Government officials $25.86 \%, 19.83 \%$ students, $13.79 \%$ professionals whereas only $6.90 \%$ of entrepreneurs.

Characteristics of the area of origin that showed $97.50 \%$ of respondents came from the province of North Sulawesi (Manado, Minahasa, Sangir Bolmong and Bitung), while from outside the area was $2.50 \%$ coming came from Bogor and Ternate). This suggests that the local communities, especially those in Manado and its surroundings are the main culinary connoisseurs native to the area.

Based on validity and reliability test to the questioner was valid where as account $r>r$ table (sig $0.05, n=20$, df namely 0.444 ), average of the $r$ critic is 0.7739 . The reliability test was reliable where Cronbach's Alpha is $>0.60$ and average of number of it is 0.6872 .

\section{Assessment based on the 5 Dimensions of Service Aspects of waitresses dressed clean and tidy}

The waiter is a person who plays an important role in preparing the table service to guests. The waiter should have a clean appearance, and hospitality to welcome guests. Then the arrangement of the dining room was clean with regular tableware and available menu. Reception it's polite and nice to guests when guests came would greatly affect the impression (image) which was nice of guests. Although sometimes the taste of the food is not too bad, but because it looks good service from the waitress who led guests are also interested in the restaurant dining place. The analysis showed that the 116 respondents indicated $51.72 \%$ are expecting, $48.28 \%$ expect. While the performance of services resulted in $41.38 \%$ satisfied, very satisfied $3: 45 \%$, while the remaining $31.03 \%$ is quite satisfied, $20.69 \%$ less $3: 45 \%$ satisfied and dissatisfied. These conditions need to be observed by the manager of the restaurant, where necessary enhance to performance waitresses.

\section{Aspects of waitresses setting up chairs and completeness of eating at the table}

From the aspect of waiters setting up chairs tables and other equipment for the preparation of a meal of respondents gave the hope: $48.28 \%$ are expecting, $3.45 \%$ expect and reasonably expect. While the performance of services showed: $37.93 \%$ quite satisfied, $34.48 \%$ satisfied, $3.45 \%$ and very satisfied. For the category of negative results showed $20.69 \%$ less satisfied, and 3:45\% dissatisfied. This means there is still a shortage of waiters in preparing creative layout and complete seat of dining table.

Aspects of waitresses prepared with a list of menu

Preparation and knowledge of diet is needed by a waitress. Readiness with menus in hand indicates that the waitress is ready to serve the guests who will come to enjoy dishes that will be sold. Expectations of respondents to the waitress, who prepared the menu list, i.e. $55.17 \%$ expect, $34.48 \%$ so expect, and $6.90 \%$ is quite expect. While the resulting performance is: $51.72 \%$ satisfied, $3: 45 \%$ very satisfied, while $27.59 \%$ were quite satisfied. Poor performance is: $13.79 \%$ less satisfied and, $3.45 \%$ more dissatisfied. This shows that the waitresses must constantly be reminded to prepare a menu list at the time of serving guests.

\section{Aspects of waitresses assured conformity with the food on the menu ordered}

In this aspect it appears that the respondent gives hope that are: $75.86 \%$ are expecting, $20.69 \%$ expect and $3: 45 \%$ quite expecting. While the performance of services produced in which: $10.34 \%$ dissatisfied, $13.79 \%$ less satisfied, $34.48 \%$ fairly satisfied, $37.93 \%$ satisfied and $3.45 \%$ very satisfied. This assessment was given by the respondents are sometimes caused by negligence in caring waitresses or waiter does not repeat order to a guest at the time of booking guests ordering food.

\section{Aspects of waitresses serve exactly the food ordered by guests}

This aspect shows respondents' answers to the right attitude right of waitresses serving food were booked guests, i.e. $51.72 \%$ are expecting, $41.38 \%$ were expecting, and the same percentage $3: 45 \%$ to the answer not expect and enough. While the assessment of performance, namely: $6.90 \%$ dissatisfied, $13.79 \%$ less satisfied, $37.93 \%$ fairly satisfied, $34.48 \%$, satisfied and $6.90 \%$ very satisfied. Results of the assessment of respondents 
are still a value that indicates the disappointment of the guests to order food that is certainly far from the time it is delivered at the time of ordering food. (f) Aspects of waitresses skilled to serve the guests order

In this aspect respondent seem to give hope that is: $68.97 \%$ very important, $24.14 \%$ expect and $6.90 \%$ quite expecting. While the resulting performance show: $3.45 \%$ dissatisfied, $41.38 \%$ less satisfied, $44.83 \%$ fairly satisfied, $6.90 \%$ satisfied and $3.45 \%$ very satisfied. From these results the gap is far enough between the positive attitude of hope and the resulting service performance. This indicates, there should be training for waitresses, remember skills in the general hospitality industry is the most fundamental thing for a waiter in serving guests.

\section{Aspects of waitresses willing to help guests}

This aspect of the respondents expects the waiter to always be willing to help guests i.e. $48.28 \%$ are expecting, $44.83 \%$ expect, and the percentage is $3.45 \%$ share fairly and do not expect. While the expected performance are: $3: 45 \%$ dissatisfied, $20.60 \%$ less satisfied, $37.93 \%$ fairly satisfied, $34.48 \%$, satisfied and $3.45 \%$ very satisfied. These results indicate that the waitress should be responsive to the needs of guests, so managers need to provide training for the waitresses.

\section{Aspects of waitresses serve in a fast time}

This aspect indicated the respondent's answers: $55.17 \%$ are expecting, $41.38 \%$ expect and $3.45 \%$ quite expecting. While performance is obtained: $3.45 \%$ dissatisfied, $10.34 \%$ less satisfied, sharing the same percentage is $41.38 \%$ sufficient and satisfactory, while $3.45 \%$ very satisfactory. The management should give a warning to the waiter to deliver services quickly and do not delay in serving guests or make guests wait long for things that need to be done fast.

\section{Aspects of waitresses are ready and alert serve guests}

For guests who enjoy the food provided restaurant, always think to be treated better by the waiters, where guests expect waitresses always give special attention, alert to the needs of guests. The respondents answer: $58.62 \%$ are expecting,
$34.48 \%$ expect, and $6.90 \%$ reasonably expect. While performance is obtained: $6.90 \%$ dissatisfied, $31.03 \%$ less satisfied, $27.59 \%$ fairly satisfied, $31.03 \%$ are satisfied and $3.50 \%$ very satisfied.

\section{Aspect of waitresses master restaurant menu}

This aspect assesses menu knowledge of waiter where the respondents answered: $65.52 \%$ are expecting, $27.59 \%$ expecting and $6.90 \%$ quite expecting. This is a fundamental aspect of how the waitress could serve well, when they do not control the content of the menu that can be held. However, the performance found base on the respondents answers: $3.45 \%$ dissatisfied, $27.59 \%$ less satisfied, $13.79 \%$ fairly satisfied, $48.28 \%$ satisfied and $6.90 \%$ very satisfied.

\section{Aspects of waitresses provide information about the menu}

This aspect is urgent for guests who enjoy the food, and should not be allowed. Sometimes there is a food menu which up, and no information by the waitresses. When guests book and have to wait a long time, and inform that the ordered menu is up, it causes disappointment have for guests. Expectations of respondents to this aspect are as follows: $75.86 \%$ are expecting, $20.69 \%$ expect and $3.45 \%$ quite expecting. Meanwhile, respondents' assessment of the performance was produced was $6.90 \%$ dissatisfied, $17.24 \%$ less satisfied, fairly satisfied $20.69 \%, 48.28 \%$ and $6.90 \%$ satisfied very satisfied.

\section{Aspect of waitresses able to communicate well}

Related to the communication aspect, it is fundamental where the waitresses, equipped with the essential good way of talking to guests, because guests are consumers who always ask for good service from the waitresses. It is necessary to understand the culture of origin which is sometimes greatly affect oracle of the people to communicate, especially in high levels of work pressure, this will greatly affect the emotions of the workers. Expectations of respondents: $65.52 \%$ are expecting, $27.59 \%$ expect and $6.90 \%$ enough. Meanwhile, respondents' assessment of performance is: $3: 45 \%$ dissatisfied, 27.59 less satisfied, $13.79 \%$ fairly satisfied, $48.28 \%$ satisfied and $6.90 \%$ very satisfied. 
Poor Service in Local Restaurants Manado (Towoliu et al.)

\section{Aspect of waitresses being friendly, polite and orderly while serving}

In this aspect, respondents rates are: $79.31 \%$ are expecting, $17.24 \%$ expect and $3.45 \%$ reasonably expect, while performance assessment by respondents: $6.90 \%$ dissatisfied, $17.24 \%$ less satisfied, $20.69 \%$ were quite satisfied, $48.28 \%$ satisfied and $6.90 \%$ very satisfied. Restaurants may get a good image at a time when the guest entered already greeted with a friendly smile, polite and orderly serve guests. Because first impressions are decisive guests can feel at home even sit back enjoy a menu that is sold. So from these results is actually reminiscent of the manager to always tell the waiter when guests come to their restaurant.

\section{Aspect of waitresses was able to hear guest complaints}

This aspect may sometimes be overstated, and may be considered when guests arrive; guests book the existing food on the menu. But sometimes there are guests who need special attention this case the possibility of a particular disease that may need to remind the waiter to tell the chef to decrease slightly from the usual standard processed by the chef to give to guests. The waiter should always pay attention to this. Ratings given by respondents are: $48.28 \%$ expect and $51.72 \%$ crave. While the performance appraisal is: $10.34 \%$ dissatisfied, $13.79 \%$ less satisfied, $27.59 \%$ fairly satisfied, $41.38 \%$ satisfied and $6.90 \%$ very satisfied. This aspect is actually must always be a concern for waitresses and should not be underestimated.

\section{Aspect of waitresses was able to understand guest suggestions}

Sometimes waiters consider themselves more knowledgeable than guests who come to eat, and even less likely to want to hear or understand a suggestion, or even angry and tend to ignore the show busyness and irresponsive. In terms of advice could have been a good improvement in performance. The respondents' expectations following aspects: $68.97 \%$ and expect, $31.03 \%$ crave. While performance is assessed as: $10.34 \%$ dissatisfied, $24.14 \%$ less satisfied, $27.59 \%$ fairly satisfied, $31.03 \%$ satisfied, and $6.90 \%$ very satisfied.

\section{Aspect of waitresses able to provide solutions guest complaints}

In this aspect, sometimes was not controlled well by a waitress that resulted restaurants lose prospective guests to enjoy a dish. This can be seen when the guests are preparing dishes turns table ordered menu is up, and the waitress who serves merely convey and do not provide an alternative solution similar menu is probably better than that booked by guests that have been depleted. Expectations of respondents to the question: $51.72 \%$ so expect and $48.28 \%$ expecting. While the performance appraisal can be: $10.34 \%$ dissatisfied, $13.79 \%$ less satisfied, $27.59 \%$ fairly satisfied, $41.38 \%$ satisfied and $8.69 \%$ very satisfied.

\section{Aspect of waitresses provide clear information to the guest services}

Information services is strongly needed by a sometimes waitress who received an order different menus with the waitress who serves the table, and could be wrong at the time of delivery of the food menu, as this aspect should not be underestimated by the manager and must be considered. Therefore in this aspect of respondent's rate: $72.41 \%$ are expecting, and $27.59 \%$ expecting. While performance assessments show: $10.34 \%$ dissatisfied, $24.14 \%$ less dissatisfied, $27.59 \%$ fairly satisfied, $31.03 \%$ satisfied and $6.90 \%$ very satisfied. The manager of the restaurant should pay attention to this case should not be allowed because it would create a bad image for the local culinary industry that is the city of Manado.

\section{Quality of Service}

Furthermore, various indicators of these aspects of service quality had been seen from the waitress at a local restaurant. If the perceived service is lower than expected, then the perceived poor quality of service. From the results of questionnaires distributed to guests who enjoy original culinary Manado. The results are based on a perception of service quality local waitresses are satisfied by 3.11 while guest ratings expectations of service quality is 4.47 . The rate of guests' expectations and service performance showed in Table 1. 
Table 1. Average Value Expectations, Service Performance of Local Waitress at two locations culinary, 2015

\begin{tabular}{|c|c|c|c|}
\hline Indicator & $\begin{array}{c}\text { Average1 } \\
\text { ¿EV }\end{array}$ & $\begin{array}{c}\text { Average2 } \\
\text { ¿PV }\end{array}$ & $\begin{array}{c}\text { Average } \\
\Sigma \mathrm{SV}\end{array}$ \\
\hline \multicolumn{4}{|l|}{ Tangible } \\
\hline a. Aspects of waitresses dressed clean and tidy & 4.52 & 3.17 & -1.34 \\
\hline b. Aspects of waitresses setting up chairs and completeness of eating at the table & 4.34 & 3.10 & -1.24 \\
\hline c. Aspects of waitresses prepared with a list of menu & 3.93 & 3.34 & -0.59 \\
\hline \multicolumn{4}{|l|}{ Reliable } \\
\hline d. Aspects of waitresses assured conformity with the food on the menu ordered & 4.62 & 3.00 & -1.62 \\
\hline e. Aspects of waitresses serve exactly the food ordered by guests & 4.24 & 3.14 & -1.10 \\
\hline f. Aspects of waitresses skilled to serve the guests order & 5.66 & 2.62 & -3.03 \\
\hline \multicolumn{4}{|l|}{ Responsiveness } \\
\hline g. Aspects of waitresses willing to help guests & 4.21 & 3.14 & -1.07 \\
\hline h. Aspect of waitresses serve in quick time & 4.41 & 3.28 & -1.14 \\
\hline Aspects of waitresses are ready and alert serve guests & 4.31 & 2.86 & -1.45 \\
\hline \multicolumn{4}{|l|}{ Assurance } \\
\hline j. Aspect of waitresses master restaurant menu & 4.38 & 3.28 & -1.10 \\
\hline k. Aspects of waitresses provide information about the menu & 3.03 & 3.24 & 0.21 \\
\hline I. Aspect of waitress able to communicate well & 5.21 & 3.28 & -1.93 \\
\hline m. Aspect of waitress being friendly, polite and orderly while serving & 4.66 & 3.24 & -1.41 \\
\hline \multicolumn{4}{|l|}{ Emphaty } \\
\hline n. Aspect of waitress was able to hear guest complaints & 4.48 & 3.10 & -1.38 \\
\hline o. Aspect of waitress was able to understand guest suggestions & 4.69 & 2.90 & -1.79 \\
\hline p. Aspect of waitress able to provide solutions guest complaints & 4.52 & 3.21 & -1.31 \\
\hline q. Aspect of waitresses provide clear information to the guest services & 4.72 & 3.00 & -1.72 \\
\hline Account of value & 75.93 & 52.90 & -23.03 \\
\hline Account of average value & 4.47 & 3.11 & -1.35 \\
\hline
\end{tabular}

From the ratings in the table it appears that almost all aspects of the show minus values. Only one aspect shows the positive value, and the aspect is waitresses provide information about the menu to the guest. But this aspect does not affect the overall the quality of service. So the conclusion of service quality of local waitresses is still bad. Where guest do not satisfied with the service and the local waitress service performance when viewed from the average total satisfaction with the service, looks average guests have the satisfaction level of -1.35 .

One thing needs to be explored further that waitresses to the local restaurant has same tendency in serving the guests are weak in terms of service standards. It is also a tendency in many places both in Asia and in Europe (especially Eastern Europe) $[7,8]$.

Unique local food with good service is affecting tourists to visit a tourist destination [15]. Besides that, the offers services of a restaurant is important, the food quality and also the skills and state of the atmosphere of the restaurant where the guests feel welcome, indirectly affects the destination [16].
While the satisfaction rating related with the components of a destination. As for the components of these destinations are an attraction, infrastructure, restaurants, and service performance [17]. Here can be analyzed that the restaurant and the service performance an indicator for the success of tourism destinations

Views of the marketing mix that local food and landscape unique area affecting a destination, where tourists feel that it really is in a tourist destination that is in direct contact with the local culture, where tourists have to eat at least two or three times a day. From some early research it can be concluded that the development of a local restaurant, which also affects the human empowerment rating in determining the tourist destination. The poor quality of service of local workers will affect also the development of destinations.

Connected with research where the results of a local restaurant waitress service quality in Manado is located on the value of -1.35 , signaled that the need to restore the quality of service. It is because the quality of services at a local restaurant is part of the development of a destination. 
Supposedly in the pattern of tourism development approach, not only be approached from the standpoint of the location will be developed but also human activities (local resources) should also be considered.

Solutions should move in order to improve the quality of service waitress at a local restaurant is stiffened by recruiting local workforce has the basic skills of food and beverages services namely recruitment of tourism vocational school graduates. But the conditions of new tourist areas certainly faced with a shortage of schools that provide education skills of food and beverages services. The short term planning solution that must be done is to conduct basic training for employees who are already working in the industry of culinary gradually and hope the workers who have been trained can teach to staff who have not received training opportunities, or they become role patron or agent of change for staff yet training opportunities.

The city authorities in long-term planning skills necessary to allocate the opening of school-based tourism skills, so the link between the vision and mission of the city is a tourist town supported by the provision of local workforce competent in the field of tourism.

Connected with the problems in this case, of course, need a short-term solution that must be done by the city government to support service improvements at a local restaurant in the city of Manado. The government should suggest to the owners of local eateries in the city of Manado so that the waitress had to be trained to support the quality of service to guests. Quality service to the guests is not just in food products being served but also about skill and empathy towards guests. Importance of readiness of employees/staff before starting the activity in the restaurant urgently needed. It is difficult to prepare a good performance if the waitress did not have competence in service. The restaurant employees should have minimal training, such as technical skills, product knowledge and interpersonal skills [18].

Training methods suggested in the form on the job or off the job training. Methods of training to be undertaken are depending on the availability of time and working conditions and the situation of employment. When the method of on the job training that will be implemented then the method of job rotation and demonstration and example, it is suitable to the type of work for the waitresses. This means that practical training is directly practiced, would make it easier for employees to implement in their work. Practically, training method requires the job list for every employee. It was easier for supervisors and staff to view and assess each procedure steps work already done [19]. When on the job training could not be done then the second solution is off the job training. Especially for off the job training, the proper method is: a video presentation, vestibule method and role play and simulation.

\section{CONCLUSION}

Guest rating the performance of services and service quality expectations will guest waitress. Almost all aspects of the show minus values -1.35 , indicates that the guest is not satisfied with the services provided by the waitress.

Some suggestion that need to be considered, among others: general manager should improve the quality of service by improving every aspect dimension in the quality of services provided to guests. Manado City Government through the Department of Tourism and Culture should encourage local culinary entrepreneurs to pay attention to provide training to local waiters in local culinary industry. As a suggestion for solving the problem of weak local restaurant waitress service quality training is done waitresses. The training can be done on the training and off the job training. For the method of on the job training and job rotation, the demonstration and example, is very suitable for this type of work waiter, while off the training genius proper method is a video presentation, vestibule method and role play and simulation. The next suggestion of this study is it necessary to add the training model for the waitresses.

\section{ACKNOWLEDGEMENTS}

The author regards to the Ministry of Research, Technology and Education via Research Institution in State Polytechnic of Manado which funded this research. 


\section{REFERENCES}

[1] Statistic Centre Manado. Manado statistic number. Available at: https://manadokota. bps.go.id.

[2] Hakim, L., M. Soemarno and S. K. Hong. 2012. Challenges for conserving biodiversity and developing sustainable island tourism in North Sulawesi Province, Indonesia. Journal of Ecology and Environment 35(2), 61-71.

[3] Richards, G. 2003. Tourism and labour mobility in the European Union. Tourism Recreation Research 28(1), 77-86.

[4] Parasuraman, A., V. A. Zeithaml and L. L. Berry. 1995. Moving forward in service quality research: measuring different customerexpectation levels, comparing alternative scales, and examining the performancebehavioral intentions link. Marketing Science Institute Cambridge Massachusetts, 41-42.

[5] Nasution, M. N. 2004. Total service management: manajemen jasa terpadu. Ghalia Publisher. Indonesia.

[6] Ramaswamy, R. 1996. Design and management of service processes: keeping customers for life. Addison-Wesley. UK.

[7] Tan, Q, A. Oriade and P. Fallon. 2014. Service quality and customer satisfaction in Chinese fast food sector: a proposal for CFFRSERV. Journal of Advances in Hospitality and Tourism Research (AHTR) 2(1), 30-53.

[8] Markovic, S., S. Raspor and K. Šegaric. 2010. Does restaurant performance meet customers'? Journal of Tourism and Hospitality Management 16(2), 181-195.

[9] Parasuraman, A., L. L. Berry and V. A. Zeithaml. 1991. Refinement and reassessment of the SERVQUAL scale. Journal of Retailing 67(4), 420-450.

[10] Fitzsimmons, J. A. and M. J. Fitzsimmons. 1997. Service management for competitive advantage. Mc Graw Hill Inc. USA.

[11] Olsen, M. D., R. Teare and E. Gummesson. 1996. Service quality in hospitality organizations. Cassell. London.

[12] Grönroos, C. 1998. Marketing services: the case of a missing product. Journal of Business and Industrial Marketing 13(4/5), 322-338.

[13] Tjiptono, F. 2004. Service, quality and satisfaction. Andi Publisher. Yogyakarta.
[14] Riduwan. 2009. Skala pengukuran variabelvariabel penelitian. Alfabeta. Bandung.

[15] Björk, P., and H. Kauppinen-Räisänen. 2016. Local food: a source for destination attraction. International Journal of Contemporary Hospitality Management 28(1), 177-194.

[16] Walter, U., I. M. Jonsson and J. Sundqvist, 2015. Eating out: a study of visitors' value creating activities related to food and meals. In: $24^{\text {th }}$ Nordic Symposium of Tourism and Hospitality Research.

[17] Huang, S. S., Afsharifar, A., \& van der Veen, R. 2015. Examining the moderating role of prior knowledge in the relationship between destination experiences and tourist satisfaction. Journal of Vacation Marketing, 1356766715618996.

[18] Pratten, J. D. 2003. The importance of waiting staff in restaurant service. British Food Journal 105(11), 826-834.

[19] Arduser, L. and D. R. Brown. 2005. The waiter and waitress and waitstaff training handbook: a complete guide to the proper steps in service for food and beverage employees. Atlantic Publishing Company. 